\title{
Shariah-compliant capital asset pricing model: New mathematical modeling
}

\author{
Abdelkader Derbali* \\ Higher Institute of Management of Sousse, University of Sousse, Tunisia \\ E-mail: derbaliabdelkader@outlook.fr \\ *Corresponding author

\begin{abstract}
Abderrazek El Khaldi
Faculty of Economic Sciences and Management of Sousse, University of Sousse, Tunisia
\end{abstract} \\ E-mail: abderrazek.elkhaldi@yahoo.fr
}

\section{Fathi Jouini}

Faculty of economic and management of Sousse,

Sousse University, Tunisia

Email: fathi_75@hotmail.fr

\begin{abstract}
The main objective of our paper is to propose a novel approach in pricing Islamic financial assets in accordance to shariah, advocated by contemporary investment theories of Markowitz's Mean-Variance Analysis and CAPM. The shariah- compliant Capital Asset Pricing Model that we developed with a few changing's of the traditional Capital Asset Pricing Model is integrating zakat, purification of return and exclusion of short sales. Then, we utilize a sample composed of 10 shariah-compliant public listed companies in Bursa Malaysia. The empirical results find that the proposed Islamic CAPM is appropriate and applicable in investigating the linkage amongst risk and return in the Islamic stock market. Our investigation contributes to existing body of knowledge by presenting an algorithm and mathematical modelling of the shariah-compliant CAPM which has been lacking in the literature of Islamic finance.
\end{abstract}

Keywords: CAPM; shariah; Islamic finance; zakat; purification

Biographical notes: Dr. Abdelkader Derbali is an Assistant Professor in Finance at the Higher Institute of Management of Sousse in University of Sousse, Tunisia. He is one of the Editorial Board Members in the Journal of Energy Markets, International Business Review, Cogent Economic \& Finance, Journal of Asset Management, International Review of Applied Economics, African Journal of Accounting, Auditing and Finance, and African Journal of Economic and Sustainable Development. His research interests include Risk Management, Systemic risk, International finance, Capital markets and institutions, Banking and market microstructure and Islamic Finance. He has published articles, among others, in Research in International Business and Management, Cogent Business \& Management, Cogent Economic \& Finance, Journal of Chinese Governance, The Chinese Economy, Journal of Energy Markets, African Journal of Accounting, Auditing and Finance, International Journal of 
Economics and Accounting, International Journal of Critical Accounting, and International Journal of Trade and Global Markets.

Dr. Abderazzek El Khaldi is an Assistant Professor in Finance at the Faculty of Economic Sciences and Management of Sousse in University of Sousse, Tunisia. His research interests include Risk Management, Corporate finance, International finance, Capital markets and institutions, Banking and market microstructure and Islamic Finance. He has published articles, among others, in European Journal of Economics, Finance and Administrative Sciences, International Research Journal of Finance and Economics, Procedia Economics and Finance and British Journal of Economics, Management \& Trade.

Dr. Fathi Jouini is an assistant Professor in the Department of Finance.. He received his MA and $\mathrm{PhD}$ degrees from Faculty of Economics and Management of Tunis, El Manar University. Regarding his academic practice, he has taught and supervised students on various academic levels, i.e. bachelor, master. His research interests include corporate governance, earning quality, corporate finance, and credit risk. He has published many articles in peer-reviewed journals (Afro-Asian Journal of Finance and Accounting, Mediterranean Journal of Social Sciences, journal of economic and social studies, international business research, international journal of economics and financial issues. 


\section{Introduction}

The link between ethical finance and financial performance is difficult to establish. In terms of risk-adjusted returns, most studies do not find significant differences between ethical and conventional investments (Bauer et al., 2007). The financial literature reports that performance evaluation depends on several variables, including benchmark selection, performance metrics, and number of ethical filters used, investment style, geographic factors, and economic Investment horizon.

The foundation for modem investment theories were studier for the first time by Markowitz (1952), who concluded that a portfolio is mean-variance efficient if it has the highest expected (mean) return $\overline{R_{p}}$ for a given variance (risk) $\sigma_{p}^{2}$, or, similarly, if it has the negligible variance for a given expected return [1]. Building on Markowitz's earlier work, Sharpe (1964) develop the CAPM (Capital Asset Pricing Model) for valorizing risky assets; Lintner (1965), Mossin (1966), Fama and French (1992) and Black et al. (1972), all made some contributions by extending the model.

Roll (1977) investigates the test of two-parameter asset pricing theory. According to the mathematical equivalence among the individual return/'beta' linearity nexus and the market portfolio's mean-variance efficiency, any valid test presupposes complete knowledge of the true market portfolio's composition. This implies, inter alia, that every individual asset must be included in a correct test. Errors of inference inducible by incomplete tests are examined and some ambiguities in published tests are explained.

Despite these criticisms, Markowitz's (1952) model is at the root of scientific developments in finance, and has paved the way for further work on performance evaluation, Birth to several models. Thus, one-factor or multifactorial models have emerged with the work of Sharpe (1963, 1964), Lintner (1965), Treynor (1965) and other models, including those of Ross (1976) Fama and French $(1992,1993)$ and Carhart (1997).

The progression of Islamic finance leads to the fundamental question whether or not the practice of modern investment theories and analyses-Markowitz's Mean Variance Analysis and Capital Asset Pricing Model (CAPM), are in accord to shariah and could be employed in pricing Islamic financial assets [2]. Usmani (2007) urges that the Islamic financial institutions should liberate themselves from this practice.

A few researchers have agreed that Capital Asset Pricing Model can be applied in Islamic finance (Selim, 2008; Hakim et al., 2016). One of the variables in CAPM requires the presence of a risk-free interest rate which known as risk-free return. However, a risk-free 
interest rate is not shariah compliant as Islam prohibits the payment or acceptance of interest charge. So theoretically there is no equivalent of risk-free interest rate in Islamic markets.

El-Ashker (1987) establishes a theoretical framework of the traditional CAPM in pricing assets by changing the risk-free return by a zakat rate on pricing assets of $2.5 \%$ [3]. Then, it is a minimum rate of return from assets where investors and traders would accept for investments and speculations to cover zakat and to expose on their risks.

Hanif (2011) suggests the using of the traditional Capital Asset Pricing Model with a minor modification by eliminating the risk-free return rate with inflation rate.

Shaikh (2010) proposes to employ the traditional Capital Asset Pricing Model in pricing treasury bonds by changing the risk-free return with NGDP (Nominal Gross Domestic Product) growth rate. But, their assumptions on risk-free return are theoretical and conjectural which is unlikely to be simulated in the financial market.

In the light of shariah compliance, the main objective of our paper is to explore key fundamentals of the Capital Asset Pricing Model (CAPM) and the set of assumptions fundamental the model in terms of its constancy to the principles of Islamic finance (shariah compliance) [4]. On the basis of CAPM, our study then shows a mathematical modeling of pricing Islamic financial assets. This particular modeling shariah-compliant CAPM is a change of the traditional CAPM that integrates principles of Islamic finance and incorporates other Islamic variables such as prohibition of short selling, purification and zakat. To do so, we utilize a data of 10 shariah-compliant public listed companies in Bursa Malaysia.

The empirical findings show that the proposed Islamic Capital Asset Pricing Model (CAPM) is suitable and pertinent in investigating the link among risk and return in the Islamic stock market. Also, our study contributes to existing body of knowledge by presenting an algorithm and mathematical derivation of the shariah-compliant Capital Asset Pricing Model (CAPM) which has been lacking in the literature of Islamic finance.

The rest of this paper is organized as follow. Section 2 presents an overview of the The assumptions of the traditional CAPM from shariah perspective. Section 3 shows econometric Modeling of the Islamic Capital Asset Pricing Model. Section 4, reports data characteristics utilized in our paper and discuss the empirical results. Then, section 5 concluding remarks. In section 6, we present the policy implications. Finally, section 7 reports the suggestions for 
future research.

\section{The assumptions of the traditional CAPM from shariah perspective}

The CAPM is a demand-side model that is based on maximizing the investor's utility function and assumes the market equilibrium. This model is relying on a set of assumptions introduced by Markowitz (1952) with a number of other additional assumptions set introduced by Sharpe (1964) and Lintner (1965).

Based on Elton et al. (2014), the assumptions are as follows: There is no transaction cost; the assets are considerably divisible; the nonexistence of personal income tax; an investor cannot influence the price of a stock by his buying and selling actions; investors' decisions are solely in terms of expected values and variance of returns; unlimited short sales are allowed; unlimited lending and borrowing at the riskless rate; and homogeneity of expectations and all assets are marketable.

In this context, we present an overview of the assumptions under which the Capital Asset Pricing Model was derived, in terms of Islamic finance (shariah compliance). Some of these assumptions may seem unlikely (unrealistic) but such simplification of reality make the Capital Asset Pricing Model more good from a mathematical perspective.

\subsection{No transaction cost}

The Capital Asset Pricing Model assumes 'no transaction cost' to decrease complexity of the model (Elton et al., 2014). The 'no transaction cost' assumption is not opposing with any principles of Islamic finance and shariah. But, it is levelheaded to point out that the insertion of transaction cost causes serious errors when numerous transactions are performed as in permanent-time models (Steinbach, 2001). In the same alignment of shariah, these errors could possibly lead to a violation of the principles of Islamic finance where the results of the model may be ambiguous, or unfortunately give a speculative (maysir) and extreme uncertainties (gharar) finding. Therefore, in this study, we follow the CAPM assumption of 'no transaction cost' in the proposed model.

\subsection{The absence of personal income tax}

Under Capital Asset Pricing Model it is assumed that there is no personal income tax. This assumption is not differing with any principles of Islamic finance and shariah as there is no 
concept of income tax in Islam. Conversely, Islam has a concept of zakat a religious tax for all Muslim who meet the essential criteria of assets, which is only levied on excess wealth and not on income. Consequently, it is decisive to include the provision of zakat in the proposed modelling that we shall discuss further in part 2.3.

\subsection{Divisibility and marketability of asset}

The Capital Asset Pricing Model (CAPM) assumes that the assets are infinitely divisible and marketable. In practice, it is not always possible to buy only single unit of an asset and investors are not continuously in the position of ideal liquidity. But, this assumption is meant for oversimplification of the model and compatible with the principles of Islamic finance and shariah. Some researchers find that by relaxing these assumptions lead to better empirical findings. In this study, we follow these assumptions in our proposed modelling.

\subsection{Investors ' decisions are solely in terms of expected return and variance (risk)}

All expected returns, variance and covariance should be identified so that investors can make decisions only on the basis of expected return and variance. Based on Rosly (2005), this is, in fact, in line with the Islamic principles of al-ghunm bil ghurm (there is no return without risk) and al-kharaj bil damam (profit is accompanied with responsibility). In fact, the shariah maxim of al-ghorm bil ghnom is invoke to invite investors to participate in ventures involving both risk and return such as al-bay (trading), al-ijarah (hire, lease or rent), salam (forward contract), mudarabah (silent partnership, where one of the parties provides capital and the other contributes expertise to conduct a exacting business, and musyarakah (joint venture).

\subsection{Short sales are allowed}

The assumption of short sales makes Capital Asset Pricing Model simplified for its mathematical derivation. This assumption means that assets may be held in an arbitrary amount-positive and negative. Dusuki and Abozaid (2008) study the issue of small sale, which is selling an asset the investor does not hold, and it obviously violates the principle of Islamic finance, bay'ma'dum (selling what the seller does not own). Any revenue from this activity is deemed riba and hence not shariah compliant. The constituent of speculation (maysir) involved in small sales further suggests that short selling is intolerable in Islamic finance. So, in this proposed modeling, we assume short sales are not allowed. 


\subsection{Unlimited lending and borrowing at a risk-free rate}

This assumption is very significant in developing the Capital Asset Pricing Model since this assumption lead to a piecewise linear relationship between expected return and beta for efficient portfolios. From the perspective of Islamic finance, the prohibition of interest leads to the nonexistence of risk-free assets, and the elimination of risk-free risk. But, there are cases that this assumption can be utilized in agreement to shariah, for instance, the employ of Islamic financial assets that could resemble risk-free assets such as sukuk (Islamic bonds). Omar et al. (2010) develop the utilizing of a 3-month Islamic treasury bills as a proxy for the risk-free assets.

\subsection{Homogeneity of expectation}

The Capital Asset Pricing Model assumes all investors have homogeneous expectations about expected returns, variances (risks) of assets and correlation coefficients among assets. In the existence of homogeneous expectations, investors hold the identical optimal portfolio. In Islamic finance, investors are encouraged to trade in shariah-compliant investments to produce return (or profit) in the usually accepted manner (al-ribh al-ma'ruf) and involving risk (Islahi, 1988).

Hence, it is reasonable to expect investors to assert homogeneous expectations in the market. Therefore, each asset will have a market price and it should be deemed as the price when investors have homogeneous expectation. Moreover, shariah allows tagging the price according to the market price (Omar et al., 2010); and this will lead to mutual consent, and ultimately homogeneity of expectations.

\subsection{An investor cannot affect the price of a stock by his buying and selling actions}

The homogeneity of anticipation implies that investors are price takers (no single investor can influence the price of a stock by buying and selling actions). In Islamic finance, investors cannot influence the price through their transactions. Thus, the homogeneous expectations assumption in the traditional Capital Asset Pricing Model (CAPM) is preserved and investors will constantly select a most advantageous portfolio.

Therefore, based on the above considerations, we concluded that most of the assumptions in the traditional CAPM and Markowitz's Mean-Variance Analysis are not contradictory to any 
principles of Islamic finance and therefore compliance to shariah. In this study, we propose a mathematical modelling of pricing Islamic financial assets using the traditional CAPM as our basis, with a small number of modifications, which is, integrating zakat, purification of return and exclusion of short sales.

\section{Modelling the Islamic Capital Asset Pricing Model}

In this section, we outline the assumptions underlying an Islamic capital asset pricing model. These assumptions are employed in order to propose the mathematical modelling of pricing Islamic financial assets.

i. The investors' decisions are solely in terms of expected values and standard deviation of asset returns,

ii. No transaction cost,

iii. Zakat and purification are deducted from the expected return,

iv. The assets are infinitely divisible,

v. The assets are marketable,

vi. Unlimited lending and borrowing at the sukuk profit rate or other Islamic benchmarks,

vii. Homogeneity of expectations,

viii. An investor cannot influence the price of a stock by his buying and selling actions.

\subsection{Mean-Variance under Islamic framework}

Markowitz (1952) develops a relationship among expected return and risk in a portfolio context. Let $X_{i}$ indicates the weight of asset $i$ in the portfolio $i=1,2, \ldots, N$ of a set of $N$ shariah-compliant assets which is through applying shariah screening procedure from the asset universe $I=1,2, \ldots, M$ with $i \subset I$. According to Derigs and Marzban (2008), applying qualitative screens to the entire universe of globally accessible assets to limit on the set of admissible assets is always a first step in portfolio optimization, and results in a abridged shariah-compliant assets [5]. This screening process, but, may have some advantageous consequences as it reduces excessive risk (Basov and Bhatti, 2014).

Given that all available shariah-compliant assets must be allocated, the $\mathrm{N}$ portfolio weight must add up to 1 , so: 


$$
\sum_{i=1}^{N} X_{i}=1
$$

The fundamental principle of the mean-variance is to utilize the expected return of a portfolio to represent the investment return and its variance as the investment risk. Basically, portfolio selection is the study of risk and return. This is reliable with the ethical principle of "no risk, no gain" in Islamic finance (Chapra, 2008), as stipulated in the shariah maxim al-ghunm bil ghurm (there is no return without risk).

In our study, it is useful to point out that Islamic ethically accountable investors do not face any adverse consequence from the shariah screening procedure on the asset universe; they can expect as much return for a given risk as an investor would gain from a conventional assets (Hassan et al., 2005). This is reliable with a recent study by Abbes (2012), who investigates the risk and the return characteristics of the Islamic stock markets employing a large international data of 35 countries. The results find that the shariah-compliant stock markets do not perform significantly differently, nor do they appear less risky than their conventional counterparts. Broadly speaking, the paper infers that investors can pursue investing in conventionality with shariah without sacrificing return or incur extra risk.

Therefore, we utilize the same approach in deriving the expected return $\overline{R_{p}}$, and variance of the portfolio $\sigma_{p}^{2}$ which are given by:

$$
\begin{gathered}
\overline{R_{p}}=\sum_{i=1}^{N}\left(X_{i} \overline{R_{i}}\right) \\
\sigma_{p}^{2}=\sum_{i=1}^{N} X_{i}^{2} \sigma_{i}^{2}+\sum_{i=1}^{N} \sum_{j=1}^{N} X_{i} X_{j} \sigma_{i} \sigma_{j} \rho_{i j}
\end{gathered}
$$

We represent the variance of the expected return of asset $i$ by of and the correlation coefficient between the expected returns on assets $i$ and $j$ by $\sigma_{i}^{2}$.

An investor can decrease their exposure to individual asset risk by investment a diversified portfolio of assets. Due to the ethical fundamentals of Islamic finance, for example in terms of the shariah screening procedure, it is a common faith that Islamic portfolios suffer a diversification difficulty in comparison to conventional portfolios. In opposing, advocates of Islamic finance disagree that the universe of shariah-compliant assets appears adequate for diversification to be achieved [6]. 
Now, we are integrating zakat and purification of return in equations (2) and (3). In Islamic finance, zakat and purification would naturally be connected and prejudiced by ethical principles and shariah constraints forced on investment [7].

In deriving the mathematical modelling, zakat and purification are treated as two independent entities although zakat is a subset of purification. Let $z$ denotes the zakat rate and $\partial_{i}$ denotes the individual purification rate of asset $i$. Therefore, the expected return and variance of individual asset $i$ are given by:

$$
\begin{aligned}
& E\left[(1-z)\left(1-\partial_{i}\right) R_{i}\right]=(1-z)\left(1-\partial_{i}\right) \bar{R}_{i} \\
& \operatorname{Var}\left[(1-z)\left(1-\partial_{i}\right) R_{i}\right]=(1-z)^{2}\left(1-\partial_{i}\right)^{2} \sigma_{i}^{2}
\end{aligned}
$$

After integrating zakat and purification of return, we derive the equations for the expected return $\overline{R_{p}^{\prime}}$, and variance of the portfolio $\sigma_{p}^{2}$ which are given by:

$$
\begin{gathered}
\overline{R_{p}^{\prime}}=\sum_{i=1}^{N}\left[X_{i}(1-z)\left(1-\partial_{i}\right) \overline{R_{i}}\right] \\
\sigma_{p}^{\prime 2}=\sum_{i=1}^{N} X_{i}^{2}(1-z)^{2}\left(1-\partial_{i}\right)^{2} \sigma_{i}^{2}+\sum_{i=1}^{N} \sum_{j=1}^{N} X_{i} X_{j}(1-z)^{2}\left(1-\partial_{i}\right)\left(1-\partial_{j}\right) \sigma_{i} \sigma_{j} \rho_{i j}
\end{gathered}
$$

\subsection{Deriving the Islamic CAPM}

Let us consider the problem of constructing a portfolio with the objective function of achieving maximum expected return, agreed this constraint of maximum capital to be invested. To obtain the objective function, we employ equations (6), (7) and the sukuk profit rate, as we have seen above in the assumption of unlimited lending and borrowing at the sukuk profit rate. Let $R_{s}$ denotes the sukuk profit rate of asset i:

$$
R_{s}=\sum_{i=1}^{N}\left(X_{i} R_{s}\right)
$$

The objective function is given by:

$$
\theta=\frac{\overline{R_{p}^{\prime}}-(1-z) R_{s}}{\sigma_{p}^{\prime}}
$$

Subject to the constraints $\sum_{i=1}^{N} X_{i}=1$ and $X_{i} \geq 0$ for all $i$ to avoid small sales which are not allowable in Islamic finance.

Therefore, from (9), we can write: 


$$
\theta=\frac{\sum_{i=1}^{N}\left[X_{i}(1-z)\left(1-\partial_{i}\right) \overline{R_{i}}\right]-(1-z) R_{s}}{\left[\sum_{i=1}^{N} X_{i}^{2}(1-z)^{2}\left(1-\partial_{i}\right)^{2} \sigma_{i}^{2}+\sum_{i=1}^{N} \sum_{j=1}^{N} X_{i} X_{j}(1-z)^{2}\left(1-\partial_{i}\right)\left(1-\partial_{j}\right) \sigma_{i} \sigma_{j} \rho_{i j}\right]^{\frac{1}{2}}}
$$

To maximize the objective function, we get the derivative with admiration to weight of each asset, and set it equal to zero.

Let,

$$
F_{1}(X)=\sum_{i=1}^{N}\left[X_{i}(1-z)\left(1-\partial_{i}\right) \bar{R}_{i}\right]-(1-z) R_{s}
$$

Then,

$$
\frac{d F_{1}(X)}{d X_{k}}=(1-z)\left[\left(1-\partial_{k}\right) \bar{R}_{i}-R_{s}\right]
$$

Let,

$$
F_{2}(X)=\sum_{i=1}^{N} X_{i}^{2}(1-z)^{2}\left(1-\partial_{i}\right)^{2} \sigma_{i}^{2}+\sum_{i=1}^{N} \sum_{j=1}^{N} X_{i} X_{j}(1-z)^{2}\left(1-\partial_{i}\right)\left(1-\partial_{j}\right) \sigma_{i} \sigma_{j} \rho_{i j}
$$

Then,

$$
\frac{d F_{2}(X)}{d X_{k}}=2 X_{k}(1-z)^{2}\left(1-\partial_{k}\right)^{2} \sigma_{k}^{2}+2 \sum_{j=1, j \neq k}^{N} X_{j}(1-z)^{2}\left(1-\partial_{k}\right)\left(1-\partial_{j}\right) \sigma_{k} \sigma_{j} \rho_{k j}
$$

Thus,

$$
\begin{aligned}
& \frac{d \theta}{d X_{i}}=\left[\sum_{i=1}^{N}\left[X_{i}(1-z)\left(1-\partial_{i}\right) \overline{R_{i}}-(1-z) R_{s}\right]\right] \\
& -\frac{1}{2}\left[\sum_{i=1}^{N} X_{i}^{2}(1-z)^{2}\left(1-\partial_{i}\right)^{2} \sigma_{i}^{2}+\sum_{i=1}^{N} \sum_{j \neq i}^{N} X_{i} X_{j}(1-z)^{2}\left(1-\partial_{i}\right)\left(1-\partial_{k}\right) \sigma_{i} \sigma_{j} \rho_{i j}\right]^{\frac{3}{2}} * \\
& {\left[2 X_{k}(1-z)^{2}\left(1-\partial_{i}\right)^{2} \sigma_{i}^{2}+\sum_{i=1}^{N} \sum_{j \neq k}^{N} X_{j}(1-z)^{2}\left(1-\partial_{k}\right)\left(1-\partial_{j}\right) \sigma_{k} \sigma_{j} \rho_{k j}\right]} \\
& +\left[\sum_{i=1}^{N} X_{i}^{2}(1-z)^{2}\left(1-\partial_{i}\right)^{2} \sigma_{i}^{2}+\sum_{i=1}^{N} \sum_{j \neq i}^{N} X_{i} X_{j}(1-z)^{2}\left(1-\partial_{i}\right)\left(1-\partial_{k}\right) \sigma_{i} \sigma_{j} \rho_{i j}\right]^{\frac{1}{2}} * \\
& (1-z)\left[\left(1-\partial_{k}\right) \overline{R_{k}}-R_{s}\right]
\end{aligned}
$$

Multiplying the equation above by:

$$
\left[\sum_{i=1}^{N} X_{i}^{2}(1-z)^{2}\left(1-\partial_{i}\right)^{2} \sigma_{i}^{2}+\sum_{i=1}^{N} \sum_{j \neq i}^{N} X_{i} X_{j}(1-z)^{2}\left(1-\partial_{i}\right)\left(1-\partial_{k}\right) \sigma_{i} \sigma_{j} \rho_{i j}\right]^{\frac{1}{2}}
$$


And equating $\frac{d \theta}{d X_{i}}=0$ and the rearranging give the following results:

$$
\begin{aligned}
& (1-z)\left[\left(1-\partial_{k}\right) \overline{R_{k}}-R_{s}\right]= \\
& \frac{\sum_{i=1}^{N}\left[X_{i}(1-z)\left(1-\partial_{i}\right) \overline{R_{i}}-(1-z) R_{s}\right]}{\sum_{i=1}^{N} X_{i}^{2}(1-z)^{2}\left(1-\partial_{i}\right)^{2} \sigma_{i}^{2}+\sum_{i=1}^{N} \sum_{j \neq i}^{N} X_{i} X_{j}(1-z)^{2}\left(1-\partial_{i}\right)\left(1-\partial_{k}\right) \sigma_{i} \sigma_{j} \rho_{i j}} * \\
& X_{k}(1-z)^{2}\left(1-\partial_{i}\right)^{2} \sigma_{i}^{2}+\sum_{i=1}^{N} \sum_{j \neq k}^{N} X_{j}(1-z)^{2}\left(1-\partial_{k}\right)\left(1-\partial_{j}\right) \sigma_{k} \sigma_{j} \rho_{k j}
\end{aligned}
$$

This gives,

$$
\begin{aligned}
& (1-z)\left[\left(1-\partial_{k}\right) \overline{R_{k}}-R_{s}\right]= \\
& \lambda\left[X_{k}(1-z)^{2}\left(1-\partial_{k}\right)^{2} \sigma_{k}^{2}+\sum_{i=1, j \neq k}^{N} X_{j}(1-z)^{2}\left(1-\partial_{k}\right)\left(1-\partial_{j}\right) \sigma_{k} \sigma_{j} \rho_{k j}\right]
\end{aligned}
$$

If there are homogeneous expectations, then all investors must select the same optimal portfolio. If all investors select the same portfolio, then in equilibrium, that portfolio must be a portfolio that has all assets held in the same percentage they represent of the market. Therefore, the right-hand side of the equation is given follow:

$$
\lambda(1-z)^{2}\left(1-\partial_{k}\right)\left(1-\partial_{M}\right) \sigma_{k} \sigma_{M} \rho_{k M}
$$

This gives the following expression:

$$
(1-z)\left[\left(1-\partial_{k}\right) \overline{R_{k}}-R_{s}\right]=\lambda(1-z)^{2}\left(1-\partial_{k}\right)\left(1-\partial_{M}\right) \sigma_{k} \sigma_{M} \rho_{k M}
$$

Since this must hold for all assets (all possible values of $k$ ), it must hold for all portfolios of assets including market portfolio. Then,

$$
\lambda=\frac{\left(1-\partial_{M}\right) \overline{R_{M}}-R_{s}}{(1-z)\left(1-\partial_{M}\right)^{2} \sigma_{M}^{2}}
$$

Substituting this value for $\lambda$ in equation (20) and rearranging, then, we obtain:

$$
(1-z)\left[\left(1-\partial_{k}\right) \overline{R_{k}}-R_{s}\right]=\frac{\left(1-\partial_{M}\right) \overline{R_{M}}-R_{s}}{(1-z)\left(1-\partial_{M}\right)^{2} \sigma_{M}^{2}}(1-z)^{2}\left(1-\partial_{k}\right)\left(1-\partial_{M}\right) \sigma_{k} \sigma_{M} \rho_{k M}
$$

Then,

$$
\left(1-\partial_{k}\right) \overline{R_{k}}-R_{s}=\beta_{k}\left[\frac{\left(1-\partial_{k}\right)}{\left(1-\partial_{M}\right)}\right]\left[\left(1-\partial_{M}\right) \overline{R_{M}}-R_{s}\right]
$$

Thus, 


$$
\overline{R_{k}}=\frac{1}{\left(1-\partial_{k}\right)}\left\{R_{s}+\beta_{k}\left[\frac{\left(1-\partial_{k}\right)}{\left(1-\partial_{M}\right)}\right]\left[\left(1-\partial_{M}\right) \overline{R_{M}}-R_{s}\right]\right\}
$$

Therefore,

$$
\overline{R_{k}}=\frac{1}{\left(1-\partial_{k}\right)} R_{s}+\beta_{k}\left[\overline{R_{M}}-\frac{R_{s}}{\left(1-\partial_{M}\right)}\right]
$$

Finally, we can note that the term $\partial_{M}$ is an optimal purification factor or the market purification rate. The equation for market purification rate is discussed in the next part.

\subsection{The optimal market purification rate}

In this part, we assess the optimal market purification rate $\partial_{M}$ for the market portfolio. This rate is necessary in the equilibrium model of the Islamic CAPM that we have developed above. We use the objective function and the observed market price of risk (in the capital market line) from the efficient frontier to get the purification rate for market portfolio. From equation (9), the objective function is expressed as follow:

$$
\theta=\frac{\overline{R_{P}^{\prime}}-(1-z) R_{s}}{\sigma_{P}^{\prime}}
$$

Where, the expected return $\overline{R_{P}^{\prime}}$ from equation (6) is obtained by:

$$
\overline{R_{P}^{\prime}}=\sum_{i=1}^{N}\left[X_{i}(1-z)\left(1-\partial_{i}\right) \overline{R_{i}}\right]
$$

This is subject to the constraints $\sum_{i=1}^{10} X_{i}=1$ and $X_{i} \geq 0$ for all $i$ to avoid short sales.

Therefore, the objective function for market portfolio is given by the following expression:

$$
\theta^{\prime}=\frac{(1-z)\left(1-\partial_{M}\right) R_{M}-(1-z) R_{s}}{\sigma_{M}}
$$

This gives the equation of market purification rate as follow:

$$
\partial_{M}=1-\frac{\theta^{\prime} \sigma_{M}+(1-z) R_{s}}{(1-z) R_{M}}
$$

Where, $\theta^{\prime}$ indicates the observed market price of risk on the capital market line. 


\section{Empirical Results}

Our empirical analysis is intended to serve as a proof-of-concept for applying the Islamic CAPM. We compare empirically the mean-variance framework of Markowitz and the Islamic CAPM based on the Markowitz mean-variance criterion as derived in the section 3 of our study.

We investigate empirically monthly rates of return from 10 shariah-compliant public listed companies in Bursa Malaysia and they are utilized to perform the analysis in this section. They are Hup Seng Industries, IJM Plantations Berhad, IOI Corporation Berhad, Petronas Gas Berhad, Sime Darby Berhad, Nestle (Malaysia) Berhad, Pos Malaysia Berhad, Genting Plantations Berhad, Tasek Corporation Berhad and DRB-Hicom Berhad.

The sample period is from January 01, 2003 to December 31, 2015. To serve as a benchmark, the returns on the Kuala Lumpur Composite Index (KLCI) are employed as a proxy for market portfolio returns, the return from a 3-month Malaysia Treasury Bills as a proxy for the risk-free rate in the traditional Capital Asset Pricing Model (CAPM) analysis, and the sukuk profit rate is proxied by 3-month Malaysia Islamic Treasury Bills for the analysis of the proposed Islamic Capital Asset Pricing Model.

We express the return of asset $i$ at time $t$ by the following equation:

$$
R_{i t}=\frac{P_{t}-P_{t-1}}{P_{t-1}}
$$

Where, $P_{t}$ indicates the adjusted close price at time $t$ and $P_{t-1}$ indicates the asset price of time $t-1$.

To illustrate the employ of the proposed Islamic Capital Asset Pricing Model in our paper, we compare the analysis of the traditional Capital Asset Pricing Model and the Islamic Capital Asset Pricing Model.

Let us revisit the traditional Capital Asset Pricing Model (CAPM) regression model is obtained as follow:

$$
R_{i t}-R_{f t}=\alpha_{i}+\beta_{i M}\left(R_{M t}-R_{f t}\right)+\varepsilon_{i t}
$$

Where, $R_{i t}$ indicates the return of asset $i$ at time $t, R_{f t}$ is the risk-free rate at time $t, R_{M t}$ is the 
rate of return on the market portfolio at time $t, \beta_{i M}$ is the market beta of asset $i$ and $\varepsilon_{i t}$ is the corresponding random disturbance term in the regression equation at time $t$. The $\alpha_{i}$ denotes the intercept term in the time series regression. The CAPM implies that the alpha is zero.

Monthly returns of each asset are regressed on the monthly surplus market returns to find betas for each asset. Using these betas, the expected rate of returns and the standard deviation of each asset are assessing. Table 1 presents the summary statistics for the annualized returns of each asset.

The $\mathrm{R}^{2}$, or coefficient of determination, reflects the percentage of a fund's movements that can be explained by the movements of its benchmark index. A $\mathrm{R}^{2}$ of 100 indicates that all changes in the fund's price can be explained by those of its index. On the other hand, a weak $\mathrm{R}^{2}$ indicates that a very small part of the price movements of a fund can be explained by the evolution of its benchmark index. A $\mathrm{R}^{2}$ of 35 means that only $35 \%$ of the fund's price movements are explained by changes in the index. Such a fund provides interesting diversification opportunities because $65 \%$ of its risk can be eliminated through diversification.

In our case, the various coefficients $\mathrm{R}^{2}$ are all greater than $80 \%$. Subsequently, it can be concluded that all changes in the Islamic fund price can be explained by those of their index by applying the traditional CAPM.

Table 1: Summary statistics for the annualized returns of each asset $i$ by utilizing the traditional CAPM

\begin{tabular}{|l|l|l|l|}
\hline Asset, $\boldsymbol{i}$ & $\begin{array}{l}\text { Expected rate } \\
\text { of return } \frac{R_{i}}{}\end{array}$ & Standard Deviation $\sigma_{i}$ & $\mathbf{R}^{\mathbf{2}}$ \\
\hline Hup Seng Industries & $35.96372 \%$ & 0.085050 & 0.8329 \\
\hline IJM Plantations & $14.49241 \%$ & 0.076787 & 0.8930 \\
\hline IOI Corporation & $14.52682 \%$ & 0.078124 & 0.8002 \\
\hline Petronas Gas & $11.69837 \%$ & 0.041404 & 0.8289 \\
\hline Sime Darby Berhad & $7.70236 \%$ & 0.055833 & 0.9321 \\
\hline Nestle Malaysia) & $12.50002 \%$ & 0.036194 & 0.9102 \\
\hline Pos Malaysia & $16.34169 \%$ & 0.080119 & 0.8374 \\
\hline Genting Plantations & $22.17836 \%$ & 0.088649 & 0.8510 \\
\hline Tasek Corporation & $10.30622 \%$ & 0.075129 & 0.8321 \\
\hline DRB-Hicom Berhad & $6.49814 \%$ & 0.110899 & 0.9062 \\
\hline
\end{tabular}

Finding the efficient frontier requires solving the following problem: find the portfolio 
weights $X_{1}, X_{2}, \ldots, X_{10}$ that minimize the variance of the portfolio $\sigma_{p}^{2}$ as given in equation (3), subject to the constraints $\overline{R_{P}}=\sum_{i=1}^{10}\left(X_{i} \overline{R_{i}}\right)$ and $\sum_{i=1}^{10} X_{i}=1$ allowing for small sales and with no short sales by adding a constraint $X_{i} \geq 0$. Then, Figure 1 indicates the efficient frontiers for the 10 assets used in our paper.

Figure 1: The efficient frontier for the ten assets with and without short sales using the

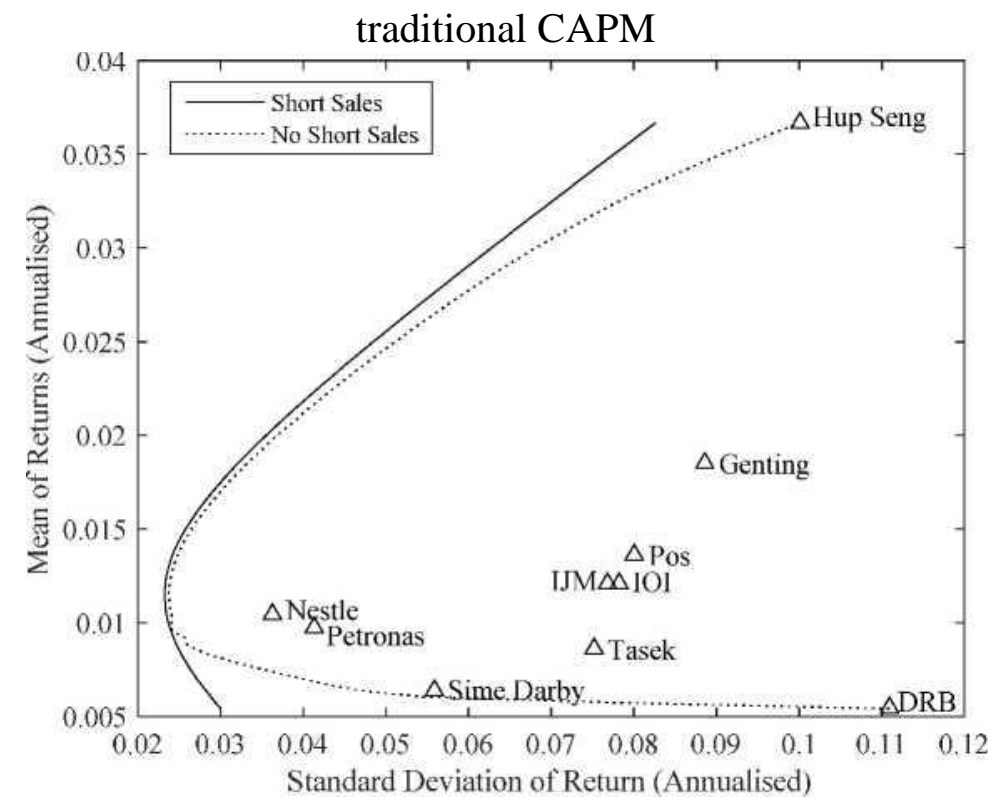

The analysis continues using the proposed Islamic CAPM. From equation (25) that has been derived previous, the proposed Islamic CAPM in the regression form is given by the following equation:

$$
R_{i t}-R_{s t}=\alpha_{i}+\beta_{i M}\left(R_{M t}-\frac{R_{S t}}{1-\partial_{M t}}\right)+\varepsilon_{i t}
$$

Where, the equation of market purification rate is obtained by the following expression:

$$
\partial_{M}=1-\frac{\theta^{\prime} \sigma_{M}+(1-z) R_{s}}{(1-z) R_{M}}
$$

Where, $R_{i t}$ indicates the return of asset $i$ at time $t, R_{s t}$ is the sukuk profit rate, $R_{M t}$ is the rate of return on the market portfolio, $\beta_{i M}$ is the market beta of asset $i$ and $\varepsilon_{i t}$ is the corresponding random disturbance term in the regression equation.

Under the Islamic framework, it is essential to subtract zakat, as well as to cleanse the income by deducting purification from the expected rate of returns of each asset. In this alignment, we utilize a zakat rate, $\mathrm{z}$ of $2.5 \%$ [8]. For purification, after removing assets from prohibited business activities that are beyond the scope of a company's primary business activities; the 
remaining assets are augmented by a purification rate. We follow a technique by Rosly (2005) where the purification rate can be intended by dividing total prohibited income by total income. The data employed for this analysis is obtained from the individual company's annual report.

Table 2 summarizes the statistics for the annualized returns of each asset using the proposed Islamic CAPM.

In our case, the various coefficients $\mathrm{R}^{2}$ are all greater than $90 \%$. Subsequently, it can be concluded that all changes in the Islamic fund price can be explained by those of their index by applying the Islamic CAPM.

Table 2: Summary statistics for the annualized returns of each asset $i$ using the proposed Islamic CAPM

\begin{tabular}{|l|l|l|l|}
\hline Asset, $\boldsymbol{i}$ & $\begin{array}{l}\text { Expected rate of } \\
\text { return } \bar{R}_{i}\end{array}$ & $\begin{array}{l}\text { Standard Deviation } \\
\sigma_{i}\end{array}$ & $\mathbf{R}^{\mathbf{2}}$ \\
\hline Hup Seng Industries & $34.32018 \%$ & 0.081163 & 0.9235 \\
\hline IJM Plantations & $13.96025 \%$ & 0.073968 & 0.9834 \\
\hline IOI Corporation & $13.92876 \%$ & 0.074908 & 0.9738 \\
\hline Petronas Gas & $11.14223 \%$ & 0.039436 & 0.9943 \\
\hline Sime Darby Berhad & $7.32271 \%$ & 0.053080 & 0.9939 \\
\hline Nestle Malaysia) & $12.00471 \%$ & 0.034760 & 0.9543 \\
\hline Pos Malaysia & $15.73173 \%$ & 0.077128 & 0.9948 \\
\hline Genting Plantations & $20.96376 \%$ & 0.083795 & 0.9994 \\
\hline Tasek Corporation & $9.84816 \%$ & 0.071790 & 0.9930 \\
\hline DRB-Hicom Berhad & $6.27348 \%$ & 0.107065 & 0.9905 \\
\hline
\end{tabular}

To produce the Markowitz mean-variance efficient frontier, we impose a constraint to avoid small sales which are not allowable in Islamic finance by using the constraints $\sum_{i=1}^{N} X_{i}=1$ and $X_{i} \geq 0$ for all $i$.

Then, Figure 2 presents the efficient frontiers for the 10 assets by utilizing the proposed Islamic CAPM. 
Figure 2: The efficient frontier for the 10 assets using the proposed Islamic CAPM

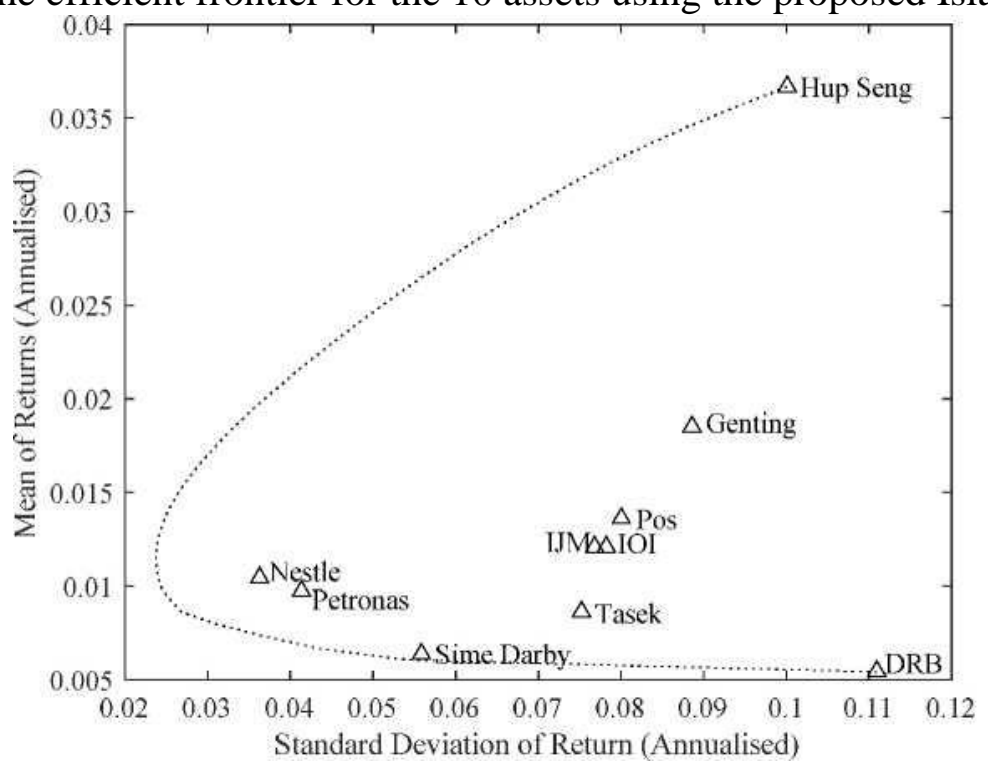

Table 3 presents the expected rate return and standard deviation of the minimum variance portfolio. For the traditional CAPM, the range of portfolio returns is among $14.04 \%$ and $36.00 \%$, and the range of portfolio risk is $7.96 \%$ to $29.41 \%$. For the shariah-compliant CAPM, the range of portfolio returns is among $13.44 \%$ and $34.32 \%$, and the range of portfolio risk is among $7.69 \%$ to $28.13 \%$. Figure 3 presents the dissimilarity among the efficient frontiers for the traditional and the proposed shariah-compliant CAPM.

Table 3: The minimum-variance portfolio

\begin{tabular}{|l|l|l|}
\hline \multicolumn{1}{|c|}{ Analysis } & Expected Rate of Return & Standard Deviation \\
\hline Traditional CAPM & $14.04 \%$ & 0.07967 \\
\hline Islamic CAPM & $13.44 \%$ & 0.07690 \\
\hline
\end{tabular}

Figure 3: The difference between the traditional and Islamic efficient frontiers

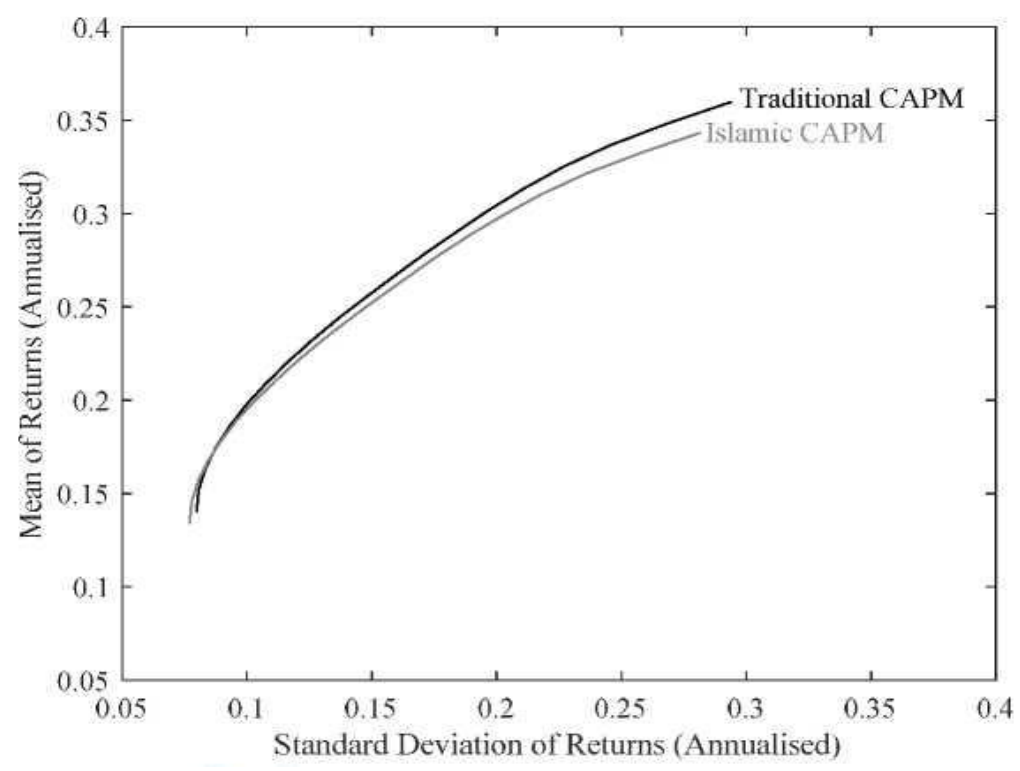

The expected rate of return and standard deviation of the minimum variance portfolio for the 
shariah-compliant CAPM are inferior to the traditional counterpart. The disparity is due to the term $(1-z)\left(1-\partial_{i}\right)$ in the Islamic model. At an inferior risk, the efficient frontier for the shariah-compliant CAPM outperforms the efficient frontier for the traditional CAPM and consequently underperforms at an elevated risk. The constraint of small sales causes the efficient frontiers to have limited higher and lesser bound.

\section{Conclusion}

The quick growth in Islamic finance urges us to not only appear for alternatives to traditional asset pricing model, but to develop its own model to assess risk and the relation among expected return and risk of sharia-compliant assets.

This study finds that the traditional CAPM is a pertinent model in Islamic finance. Most of the assumptions underlying the Markowitz's Mean-Variance Portfolio Theory are not contradictory to shariah principles. In the development of the mathematical modelling of pricing Islamic financial assets utilizing the traditional Capital Asset Pricing Model, we let some of the assumptions remain for simplification of the model.

The shariah- compliant Capital Asset Pricing Model that we developed with a few changing's of the traditional Capital Asset Pricing Model is integrating zakat, purification of return and exclusion of short sales. As a proof-of-concept, we use the data of 10 shariah-compliant public listed companies in Bursa Malaysia. The results show that the proposed Islamic Capital Asset Pricing Model (CAPM) is suitable and pertinent in investigating the link among risk and return in the Islamic stock market.

Our paper contributes to existing body of knowledge by presenting an algorithm and mathematical derivation of the shariah-compliant Capital Asset Pricing Model (CAPM) which has been lacking in the literature of Islamic finance. This study proposes a novel approach in pricing Islamic financial assets in accordance to shariah, advocated by contemporary investment theories of Markowitz's Mean-Variance Analysis and Capital Asset Pricing Model (CAPM).

\section{Policy implications}

In our case, the new Islamic CAPM can help investors to choose and to select their portfolios composed by Islamic assets. 


\section{Suggestions for future research}

For the possible future works, we can modify our sample. Also, we can use the analysis by the cross section methodologies.

\section{Acknowledgement}

I would like to thank the editor and anonymous reviewers for their supportive comments and suggestions.

\section{Notes:}

[1]: A portfolio $w^{*}$ is said to be mean-variance efficient if there exists no portfolio $w$ with $\overline{R_{p}} \geq \overline{R_{p}^{*}}$ and $\sigma_{p}^{2} \geq \sigma_{p}^{* 2}$ except itself. That is, you cannot find a portfolio that has a higher return and lower risk than those for an efficient portfolio.

[2]: The term shariah comes from the Arabic language means Islamic principles based on the Quran and the traditions of the Prophet (known as the hadith and sunnah).

[3]: Zakat is a religious tax for all Muslims who meet the necessary criteria of wealth, at a rate of $2.5 \%$ of total assets each year, for the benefit of the poor in the Muslim community.

[4]: There are 7 key principles of Islamic finance (Lewis and Algaoud, 2001; Iqbal, 1997): (i) the prohibition of riba, (ii) the basis of halal activities, (iii) the prohibition of speculative behavior (maysir) and extreme uncertainties (gharar), (iv) the obligation of zakat payment, (v) shariah board as the ruling body of Islamic finance, (vi) profit risk sharing and (vii) sanctity of contracts.

[5]: Qualitative screens are sector screens through which companies operating within specific business areas that are non-permissible under shariah are excluded. Shariah clearly defines a number of aspects which are not permissible for Muslims, such as the consumption of alcohol and pork, and thus compliant companies are not allowed to participate in business earning primarily or even partially from such activities (Derigs and Marzban, 2008).

[6]: For detail on potential diversification benefits on Islamic financial assets see Kok et al. (2009), Abd Majid and Kassim (2010) and Kamil et al. (2014). 
[7]: Zakat and purification are two different concepts. The literal meaning of zakat is to cleanse or purification, but in reality zakat operates as a religious tax, which is levied on excess wealth that a person is accumulating and has had in their possession for over a year. But the term 'purification' intended for discussion in this paper is the act of deducting the non-halal tainted income which is not permissible in shariah, from the total return on investment (Noor, 2009). Due to the complexity and the generally non-Islamic nature of the current capital market, the return obtained from both portfolios and individual assets has to be cleansed through post-investment purification practices (Elgari, 2000). It is a process in which the proportion of non-shariah compliant income is identified and donated (Derigs and Marzban, 2008). The main purification practices are dividend purification and non-halal income purification. Non-halal income includes non-operating income from interest bearing investment and income from any prohibited business activities (DeLorenzo, 2000). The purification is calculating by dividing non-halal income by the total income of asset $\mathrm{i}$ - a purification factor of asset $\mathrm{i}, \partial_{i}$.

[8]: For details see Al-Qaradawi (1999).

\section{References}

Abbes, M. (2012). Risk and return of Islamic and conventional indices. International Journal of Euro-Mediterranean Studies, 5(1), 1-23.

Abd Majid, S. and Kassim, S. (2010). Potential diversification benefits across global Islamic. Journal of Economic Coorperation and Development, 31(4), 103-126.

Ahmad Hakim, S., Hamid, Z. and Mydin Meera, A. (2016). Capital Asset Pricing Model and pricing of Islamic financial instruments. Journal of King Abdulaziz University: Islamic Economics, 29(1), 21-39.

Al-Qaradawi, Y. (1999). Fiqh az zakat: A comparative study: The rules, regulations and philosophy of zakat in the light of the Quran and Sunna. London: London.

Basov, S. and Bhatti, M. (2014). On Sharia'a compliance, positive assoratative matching, and return to investment Banking. Journal of International Financial Markets, Institutions and Money, (30), 191-195.

Bauer, R., Derwall, J. and Otten. R. (2007). The ethical mutual fund performance debate: 
New evidence from Canada. Journal of Business Ethics, 70(2), 111-124.

Black, F., Jensen, M. and Scholes, M. (1972). The Capital Asset Pricing Model: Some empirical tests. In M. Jensen, Studies in the Theory of Capital Markets (pp. 79121). New York: Praeger Publishers.

Chapra, U. (2008). Innovation and authenticity in Islamic finance. Proceeding of the 8th Harvard University forum on Islamic finance: Innovation and authenticity, April 19-20. Cambridge.

DeLorenzo, Y. (2000). Shariah supervision of Islamic mutual funds. Proceedings of the Fourth Harvard University Forum on Islamic Finance. Cambridge, MA.

Derigs, U. and Marzban, S. (2008). Review and analysis of current Shariah-compliant equity screening practices. International Journal of Islamic and Middle Eastern Finance an Management, 1(4), 285-303.

Dusuki, A. and Abozaid, A. (2008). Fiqh issues in short selling as implemented in the Islamic Capital Market in Malaysia. Journal of King Abdulaziz University, 21(2), 63-78.

El-Ashker, A. (1987). The Islamic Business Enterprise. London: Croom Helm.

Elgari, M. (2000). Purification of Islamic Equity Funds: Methodology and Shariah Foundation. Proceedings of the Fourth Harvard University Forum on Islamic Finance. Cambridge, MA: Harvard University.

Elton, E., Gruber, M., Brown, S. and Goetzmann, W. (2014). Modern Portfolio Theory and Investment Analysis, 9th ed. New Jersey: John Wiley and Sons.

Fama, E.F. and French. K.R. (1992). The cross-section of expected stock returns. Journal of finance, $47(2), 427-465$.

Fama, E.F. and French. K.R. (1993). Common risk factors in the returns on stocks and bonds. Journal of financial economics, 33(1), 3-56.

Hanif, M. (2011). Risk and return under Shari'a framework: An attempt to develop Shari'a. Pakistan Journal of Commerce and Social, 5(2). 
Hassan, A., Antoniou, A. and Paudyal, K. (2005). Impact of ethical screening on investment performance: The case of the Dow Jones Islamic Index. Islamic Economic Studies, 12(1), 67-97.

Iqbal, Z. (1997). Islamic Financial systems. Finance and development, 32(2), 42-45.

Islahi, A. (1988). Economic Concepts of Ibn Taimiyah. Leicester: The Islamic Foundation.

Kamil, N., Bacha, O. and Masih, M. (June 23-24, 2014). Is there a diversification! 'cost' o shari'ah compliance? Empirical evidence from Malaysian equities. 4th Islamic Banking and Finance Conference. Lancaster University, United Kingdom.

Kok, S., Giorgioni, G. and Laws, J. (2009). Performance of Shariah-compliant indices in London and NY stock markets and their potential for diversification. International Journal of Monetary Economics and Finance, 2(3), 398-408.

Lewis, M. and Algaoud, L. (2001). Islamic Banking. Cheltenham: Edward Elgar Publication.

Lintner, J. (1965). The valuation of risk assets and the selection of risky investments in stock portfolios and capital budgets. The Review of Economics and Statistics, 47(1), 1337.

Markowitz, H. (1952). Portfolio selection. The Journal of Finance, 7(1), 77-91.

Mossin, J. (1966). Equilibrium in a Capital Asset Market. Econometrica, 34(4), 768783.

Noor, A. (2009). A Shari'ah compliance review on investment linked takaful in Malaysia. Journal of the Islamic Research and Training Institute, 17(1), 1-20.

Omar, M., Noor, A., Meera, A., Manap, T., Majid, M. and Zain, S. (2010). Research Paper: Islamic pricing benchmark. International Shari'ah Reserach Academy for Islamic Finance (ISRA), 17.

Roll, R. (1977). A critique of the asset pricing theory`s tests Part I: On past and potential testability of the theory. Journal of Financial Economics, 4(2): 129-176.

Rosly, S. (2005). Critical issues on Islamic banking and financial markets. Kuala Lumpur: Dinamas Publishing. 
Ross, S.A. (1976). The Arbitrage Theory of Capital Asset Pricing. Journal of Economic Theory, 13(3), 341-360.

Selim, T. (2008). An Islamic capital asset pricing model. Humanomics, 24(2), 122129.

Shaikh, S. (2010). Proposal for a new economic framework based on Islamic principles. Karachi: Institute of Business Administration.

Sharpe, W. (1964). Capital asset prices: A theory of market equilibrium under conditions of risk. Journal of Finance, 19(3), 425-442 .

Sharpe, W.F. (1963). A simplified model for portfolio analysis. Management science, 9(2), 277-293.

Sharpe, W.F. (1964). Capital asset prices: A theory of market equilibrium under conditions of risk. Journal of finance, 19(3), 425-442.

Steinbach, M. (2001). Markowitz revisited: Mean-variance models in financial portfolio analysis. SIAM Review, 43(1), 31-85.

Treynor, J.L. (1965). How to rate management of investment funds. Harvard business review, 43(1), 63-75.

Usmani, M. (2007). An introduction to Islamic finance. Pakistan: Quranic Studies Publishers. 